\title{
Estados de alma
}

António Faria Vaz*

Mudam-se os tempos, mudam-se as vontades, Muda-se o ser, muda-se a confiança; Todo o mundo é composto de mudança, Tomando sempre novas qualidades.

Luís Vaz de Camões

V ivemos momentos de mudança...

O presente número da revista reflecte uma vontade e um querer.

Iniciamos hoje um novo ciclo da revista, com uma nova imagem gráfica, em que, por exemplo, cada uma das secções passará a ser identificada por cores próprias. A capa, o rosto da revista, é agora o lugar para apresentarmos o seu conteúdo e, também, para promovermos a divulgação de obras de médicos portugueses, iniciativa que se deve à amável disponibilidade e colaboração da secção de artes plásticas do Auto-Club Médico Português.

Neste número apresentamos um artigo cuja temática se centra na avaliação da satisfação dos utentes frequentadores de um Centro de Saúde, neste caso, do único Centro de Saúde académico português. Este artigo relata-nos a evolução ao longo dos últimos anos do grau de satisfação dos utentes e a sua variação temporal. A avaliação da satisfação dos utentes é, como sabemos, um dos pilares essenciais de um sistema de qualidade.

A avaliação da qualidade nos Cuidados Primários é uma das áreas de investigação a que temos consagrado significativos recursos decorrentes do trabalho realizado que muito tem contribuído para aprofundarmos os nossos conhecimentos sobre os factores que a influenciam..$^{1-3}$

Tem sido demonstrado por inúmeros estudos que a Medicina Geral e Familiar é a especialidade médica que mais contribui para a eficiência dos cuidados de saúde, existindo uma correlação positiva entre a proporção de Médicos de Família, a elevada satisfação dos doentes e a melhoria dos resultados em saúde com menores custos. ${ }^{4,5}$

*Director da Revista Portuguesa de Clínica Geral
Nos numerosos estudos que têm sido publicados, ao longo de anos, sobre a satisfação dos utentes nos Cuidados Primários, há uma tónica que persiste em todos eles, sem excepção: a insatisfação dos utentes na acessibilidade à consulta e o tempo de espera no Centro de Saúde. Esta constatação exige uma urgente reflexão sobre a nossa prática e a premência da reforma dos Cuidados Primários.

A reforma dos Cuidados Primários motiva-nos alguns estados de alma... A recente publicação do relatório da Primavera do Observatório dos Sistemas de Saú$\mathrm{de}^{6}$ acrescenta outros sentimentos... Este, no capítulo relativo aos Cuidados Primários, descreve-nos circunstanciadamente o processo histórico do desenvolvimento da Medicina Geral e Familiar em Portugal, com recurso frequente aos inúmeros diplomas e contextos que os foram determinando. A sua leitura permite-nos confirmar, de algum modo, aquilo que sempre suspeitámos:

- Em Portugal, a reflexão sobre as reformas da Saúde tem acompanhado, de um modo geral, as ideias e as propostas de reformulação dos modelos de prestação de cuidados, precursores de mudanças nos sistemas de saúde.

No entanto, por uma razão ou por outra, quedamo-nos pelos enunciados, pelos primórdios do seu desenvolvimento. Sendo raro que se concretizem essas ideias e propostas. Provavelmente porque as metodologias que têm sido adoptadas para a promoção da mudança não têm sido suficientemente fundamentadas e explicadas aos diversos actores e, não menos importante, porque a resistência à mudança tem também conseguido impedir esses desenvolvimentos, impossibilitando a adopção de modelos que promovam a eficiência dos serviços de saúde.

A presente reforma dos Cuidados Primários é, como todos sabemos, uma das reformas mais significativas do Serviço Nacional de Saúde. Sendo o seu desenvolvimento e aprofundamento essenciais ao futuro da Medicina Geral e Familiar, interessará, por isso, que a estratégia de implementação mediata conte com o envolvimento e a participação de todos, incluindo os que até 
agora, por alguma razão, ainda não se sentem motivados para o envolvimento com o processo. Importará também identificar os medos e os receios, as dúvidas e as incertezas que ainda hoje percorrem a maioria dos médicos de família, de modo a que a reforma seja, cada vez mais, o futuro de todos nós, o futuro dos Cuidados Primários de Saúde.

\section{REFERÊNCIAS BIBLIOGRÁFICAS}

1. Ferreira PL, Luz A, Valente S, Raposo V, Godinho P, Felício ED. Determinantes da satisfação dos utentes dos cuidados primários : o caso de Lisboa e Vale do Tejo. Rev Port Saúde Pública 2001; 19 (vol. temát. 2): 53-60.

2. Pisco L, Biscaia JL. Qualidade de cuidados de saúde primários. Rev Port Saúde Pública 2001; 19 (vol. temát. 2): 43-51.
3. Núcleo de Qualidade e Humanização do Centro de Saúde de Carnaxide. Avaliação da Satisfação dos Utentes do Centro de Saúde de Carnaxide. Disponível em: URL: http://www.cscarnaxide.min-saude.pt/formacao/avalsatisf/ [acedido em 26/06/2008].

4. Rosenblatt RA, Andrilla CH, Curtin T, Hart LG. Shortages of medical personnel at community health centers: implications for planned expansion. JAMA 2006 Mar 1; 295 (9): 1042-9.

5. Connally NT. When doctors lose patience. Washington Monthly, November 2007. Disponível em: URL: http://www.washingtonmonthly.com/features/2007/0711.connally.html [acedido em 27/06/2008.

6. Observatório Português de Sistemas de Saúde. Relatório da Primavera 2008. Sistema de Saúde Português: riscos e incertezas. Coimbra: Centro de Estudos e Investigação em Saúde da Universidade de Coimbra; 2008.

\section{PANTOJA ROJÃO}

Nascido em Évora, em 1943, é médico em Lisboa. Autodidacta, tem 20 anos de pintura. Bebendo nos motivos populares, no naturalismo, no impressionismo, na figuração, no abstracto e na simbologia sem seguir escola, aqui ou ali, tem exposto em vários locais da cultura.

Realizou, desde 1989, doze exposições individuais e mais de cem colectivas. Galardoado com duas Menções Honrosas e o Prémio Mário Botas de pintura da SOPEAM - 1999.

Está representado em várias colecções particulares e de entidades públicas, designadamente nos Museus de Évora, Regionais de Sintra e Guimarães, Municipais de Ovar, Portimão e Viana do Castelo, no Museu da Cidade de Lisboa, no Museu de Água da Epal e nas Câmaras Municipais de Évora, Sesimbra e Mourão, na Ordem dos Médicos e na Federação Nacional dos Médicos.

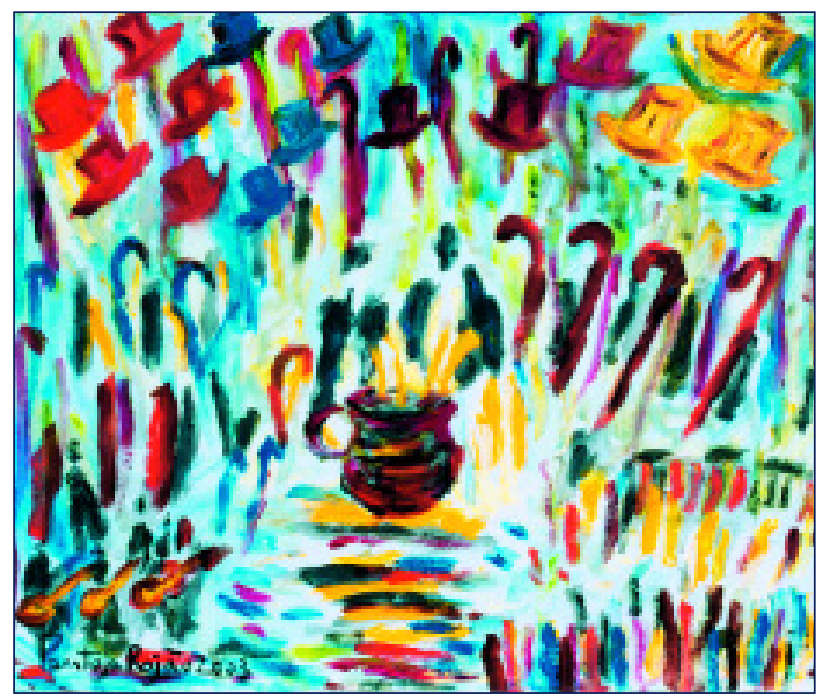

Alquimia Coimbrã

$60 \times 70 \mathrm{~cm}$-Acrílico sobre tela (2003)

Pantoja Rojão 